\title{
Resolution of vitreomacular traction following intravitreal triamcinolone acetonide injection in an eye with branch retinal vein occlusion
}

This article was published in the following Dove Press journal:

Clinical Ophthalmology

I August 2012

Number of times this article has been viewed

\author{
Göktuğ Seymenoğlu' \\ Özcan Kayıkçıŏlu' \\ Bilge Öztürk Șahin² \\ 'Department of Ophthalmology, \\ Faculty of Medicine, Celal Bayar \\ University, Manisa, Turkey; \\ ${ }^{2}$ Department of Ophthalmology, \\ Akhisar State Hospital, Akhisar, \\ Manisa, Turkey
}

\begin{abstract}
A 60-year-old woman with a past medical history of branch retinal vein occlusion presented with decreased vision and metamorphopsia in her left eye. A fundus examination revealed a tortuous retinal vein with a few retinal hemorrhages in the inferotemporal quadrant. Optical coherence tomography revealed a partially separated posterior vitreous membrane pulling up the fovea. The patient refused surgical treatment so intravitreal triamcinolone acetonide $(4 \mathrm{mg} / 0.1 \mathrm{~mL})$ was administered. The patient reported resolution of symptoms in her left eye following this treatment, but her visual acuity did not show any improvement. Optical coherence tomography scanning revealed a complete detachment of the posterior hyaloid with release of the vitreomacular traction. In patients with vitreomacular traction and branch retinal vein occlusion, the combination of the possible vitreous liquefaction and mechanical increase of vitreous volume caused by an intravitreal injection with a degree of reduction in retinal thickness may play a role in the resolution of vitreomacular traction.
\end{abstract}

Keywords: macular edema, vitreomacular traction syndrome, intravitreal injection, posterior vitreous detachment

\section{Introduction}

The vitreomacular traction syndrome (VTS) is a well-defined clinical entity caused by incomplete separation of the posterior vitreous with persistent macular attachment. ${ }^{1}$ Macular traction is frequently accompanied by cystoid changes in the neurosensory retina, causing decreased visual acuity and metamorphopsia. The traction can usually be released by vitrectomy. ${ }^{2}$ Sometimes the traction is released through the spontaneous development of a complete vitreomacular separation, although this is infrequent. ${ }^{3}$ The authors report a case of vitreomacular traction associated with branch retinal vein occlusion (BRVO) in which intravitreal administration of triamcinolone acetonide (TA) successfully released the vitreomacular traction.

\section{Case report}

A 60-year-old woman with a past medical history of BRVO presented with a 1-week history of decreasing vision and metamorphopsia in her left eye. The patient's bestcorrected visual acuity was 20/32 in the right eye and 20/400 in the left eye. A fundus examination found a tortuous retinal vein with a few retinal hemorrhages in the inferotemporal quadrant and macular edema (Figure 1). A fluorescein angiogram revealed cystoid macular edema, particularly in the temporal quadrant of the fovea (Figure 2). This finding was compatible with the diagnosis of an old BRVO, and other possible causes of chronic cystoid macular edema were excluded based on the signs,
Correspondence: Göktuğ Seymenoğlu Cengiz Topel Caddesi No 38/4,

35540 Karșiyaka, İzmir, Turkey

Tel +905323557196

Fax +902323362959

Email gseymeno@gmail.com submit your manuscript | www.dovepress.com

Dovepress

http://dx.doi.org/| 0.2147/OPTH.S3431| 


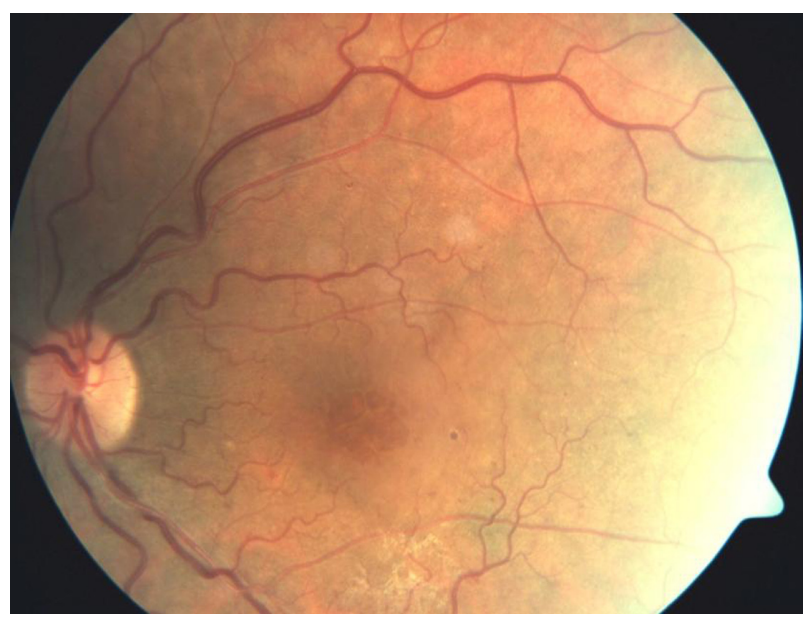

Figure I Fundus photograph of the left eye showing a tortuous retinal vein with a few retinal hemorrhages in the inferotemporal quadrant and macular edema.

fluorescein angiogram findings, and medical history of the patient. Optical coherence tomography (OCT) revealed a partially separated posterior vitreous membrane pulling up the fovea (Figure 3A). The steep posterior hyaloid curve and the thickened cystoid fovea were suggestive of vitreomacular traction. OCT also showed a large pocket of subretinal fluid, indicating the presence of sensory retinal detachment. The decreased vision was considered to have arisen from photoreceptor atrophy as a result of chronic macular edema, which is due to vitreomacular traction. The disruption of the photoreceptor inner segment-outer segment junction seen on OCT also confirmed this finding. Although pars plana vitrectomy was recommended, the patient refused surgical treatment. The patient was treated with $4 \mathrm{mg} / 0.1 \mathrm{~mL}$ of intravitreal TA (IVTA) so as to reduce macular edema and

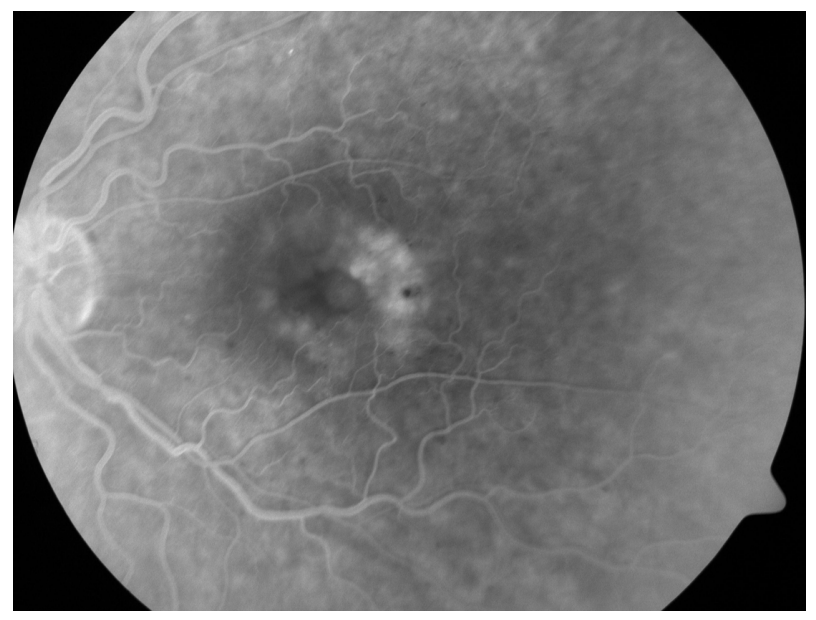

Figure 2 Fluorescein angiogram of the left eye showing cystoid macular edema, particularly in the temporal quadrant of the fovea. accelerate the development of complete posterior vitreous detachment (PVD).

Four weeks after the IVTA injection, the patient reported resolution of metamorphopsia in her left eye, but her visual acuity did not show any improvement. OCT scanning revealed a complete detachment of the posterior hyaloid with release of the vitreomacular traction (Figure 3B). There were two areas of subfoveal hyporeflectivity in the fovea that were suggestive of foveal cysts and which did not show visual improvement.

\section{Discussion}

VTS comprises a broad spectrum of frequently unrecognized clinical findings. ${ }^{1}$ The incidence rate of spontaneous resolution of VTS has been reported as $11 \%$ by Hikichi et al. ${ }^{3}$ A case of spontaneous resolution of VTS 6 weeks after intravitreal injection of ranibizumab in a patient with diabetic macular edema has also been documented. ${ }^{4}$ In the present case, resolution of the vitreomacular traction occurred in the patient, who had an old BRVO, 4 weeks after IVTA injection.

As mentioned, it is clear that spontaneous detachment may occur without any intervention, but in some cases this spontaneous detachment can take a long time to eventuate. Sivaprasad et $\mathrm{al}^{5}$ used OCT to investigate the vitreomacular relationship in patients with persistent diffuse diabetic macular edema. The patients were randomized to intravitreal injections of triamcinolone $4 \mathrm{mg}$ or to further macular grid laser treatment. The authors noted that evidence from extended follow-up of patients with perifoveal vitreous detachment suggested complete vitreomacular separation may take longer than 12 months to develop. ${ }^{5}$ It is likely that, with the passage of time, persistent cellular damage prevents significant improvement in visual acuity, despite complete vitreomacular separation and a decrease in central macular thickness. The degree of vitreous traction on the macula is thought to influence developing cystoid edema, and these changes cause a drop in visual acuity. Symptoms may worsen because traction causes retinal vascular incompetence, leakage, and cystoid changes. ${ }^{6}$ In the present case, the authors postulate that, because of the long-standing BRVO, there was macular edema before the vitreomacular traction developed, but the violent traction worsened the cystoid degeneration in the photoreceptors, thus the result of the same visual acuity after resolution of the traction. The disruption of the photoreceptor inner segment-outer segment junction, seen in the OCT scan after resolution of vitreomacular traction, 

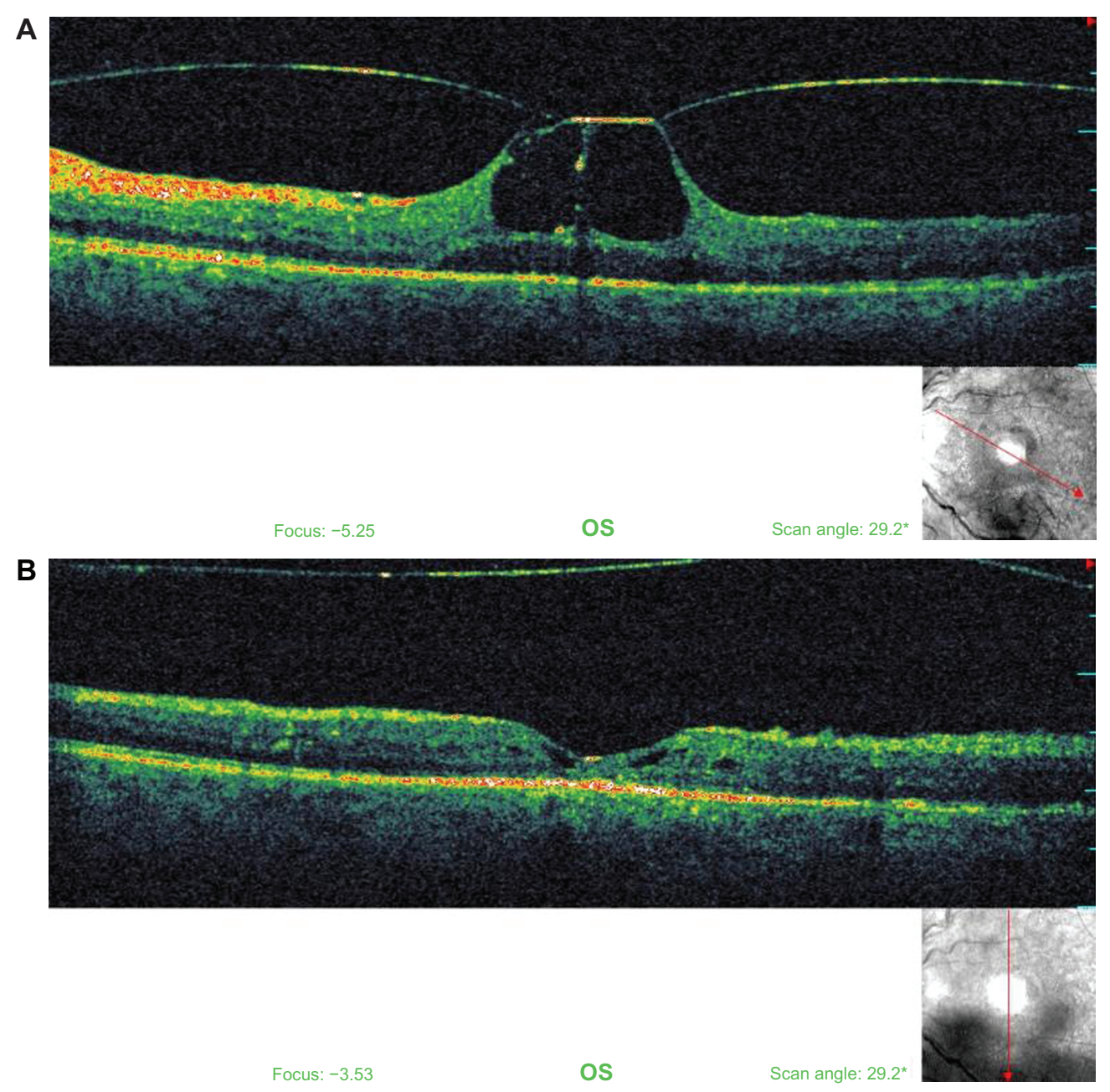

Figure 3 Optical coherence tomography images of the left eye revealing (A) a partially separated posterior vitreous membrane pulling up the fovea and (B) a complete detachment of the posterior hyaloid with release of the vitreomacular traction.

can also explain the prevention of improvement in visual acuity.

Yamada and $\mathrm{Kishi}^{7}$ examined the relationship between preoperative macular changes and surgical outcomes in VTS and found that, based on OCT findings, different types of vitreomacular traction may show different visual prognosis after surgical resolution. The authors proposed that the retinas with no cystoid macular edema but with mild cystic changes had favorable visual recovery after surgery. In comparison, the eyes in which chronic vitreous traction had led to prominent cystoid macular edema did not show visual improvement after surgery. This observation corresponds to the present authors' case. In the present case, the patient also had a large cyst that was divided by a thin septum and which showed no visual improvement after IVTA injection.

Another explanation of the lack of vision recovery may be the ocular toxicity of TA. In vitro, TA induces a clear toxic effect on retinal pigment epithelial cells, retinal Müller glial cells, and retinal neurosensory cells. ${ }^{8,9}$ It has been shown that the insoluble (crystalline) and the soluble forms of TA have different toxic effects, while the vehicle (benzyl alcohol), present in the injected preparation, may enhance the cellular toxicity. ${ }^{10,11}$ It was also shown that direct contact of insoluble TA with human retinal pigment epithelial cells (ARPE-19) induced cell death through an apoptotic-necrotic mechanism. ${ }^{10}$ Recently, Valamanesh et al ${ }^{12}$ reported that in vitro incubation of retinal cells in the presence of corticosteroids induced a specific and dosedependent reduction of cell viability. In the rat eye, 8 days after an intravitreal injection of Kenacort, the authors could detect clear lesions in retinal pigment epithelial and macroglial cells. Before cell death, the authors observed extensive cytoplasmic vacuolization in the retinal pigment epithelial cells both in vivo and in vitro. ${ }^{12}$ 
TA suppresses inflammation and reduces extravasation from leaking retinal vessels by increasing the number and the activity of tight junctions of the retinal vessels. TA also downregulates the production of vascular endothelial growth factor. ${ }^{13}$ In addition to the pharmacological effects on macular edema, IVTA may induce changes in the vitreomacular interface. The underlying mechanisms of these changes are not clear. It may be that IVTA accelerates biochemical changes in the vitreous structure associated with retinal vein occlusion and/or normal aging. Additionally, the injection procedure may trigger mechanical effects such as vitreous reflux and anterior vitreous incarceration or it may induce a local inflammatory reaction. ${ }^{14,15}$

As incomplete PVD and an attached vitreous cortex are associated with macular edema secondary to BRVO, induction of complete PVD is a major issue, both in vitreoretinal surgery and in medical retina. Agents capable of altering the molecular organization of the vitreous are a potential future option in terms of PVD induction and liquefaction of the vitreous gel, particularly with regard to the more invasive vitrectomy procedure. Recently there has been an increasing number of studies that evaluate the efficacy and safety of these agents, especially the autologous plasmin enzyme. ${ }^{16,17}$

When patients have progressive visual impairment due to VTS, vitrectomy may provide functional and anatomical improvement. In a study by Smiddy et al, ${ }^{2}$ the authors reported that $63 \%$ of patients with VTS showed improvement in visual acuity of at least two Snellen lines after pars plana vitrectomy. ${ }^{2}$ The Diabetic Retinopathy Clinical Research Network ${ }^{18}$ has reported that after vitrectomy performed for diabetic macular edema and vitreomacular traction, not only was retinal thickening reduced in most eyes but also visual acuity improved in between $28 \%$ and $49 \%$ of eyes. In the present case, the patient declined surgery. The patient was treated with IVTA in order to decrease macular edema but her visual acuity did not improve. The authors assumed this was related to the long-standing macular edema caused by an old BRVO and/or the ocular toxicity induced by TA.

In a recent study, Imasawa and Iijima ${ }^{19}$ reported a case of VTS associated with BRVO in which retinal photocoagulation applied to the ischemic retinal area successfully released the vitreomacular traction and resulted in visual recovery. ${ }^{19}$ The authors proposed that retinal photocoagulation may accelerate the development of complete PVD, resulting in the release of the vitreomacular traction. In the present case, the patient did not develop retinal neovascularization and therefore retinal photocoagulation was not performed.

\section{Conclusion}

In patients with VTS and BRVO, the combination of the possible vitreous liquefaction and mechanical increase of vitreous volume caused by an intravitreal injection with a degree of reduction in retinal thickness may play a role in the resolution of vitreomacular traction. In the case presented here, resolution of vitreomacular traction in this patient with BRVO might have been facilitated by IVTA injection. Further studies are necessary in order to determine the relationship between IVTA injection and resolution of vitreomacular traction.

\section{Disclosure}

The authors have received no public or private financial support in the form of grants, equipment, drugs, or proprietary interest in any of the products, methods, or materials mentioned in this work.

\section{References}

1. McDonald HR, Johnson RN, SchatzH. Surgical results in the vitreomacular traction syndrome. Ophthalmology. 1994;101(8):1397-1402; discussion 1403.

2. Smiddy WE, Michels RG, Glaser BM, deBustros S. Vitrectomy for macular traction caused by incomplete vitreous separation. Arch Ophthalmol. 1988;106(5):624-628.

3. Hikichi T, Yoshida A, Trempe CL. Course of vitreomacular traction syndrome. Am J Ophthalmol. 1995;119(1):55-61.

4. Rouvas A, Petrou P, Ladas I, Neamonitou G, Vergados I. Spontaneous resolution of vitreomacular traction following ranibizumab (Lucentis) injection. Eur J Ophthalmol. 2008;18(2):301-303.

5. Sivaprasad S, Ockrim Z, Massaoutis P, Ikeji F, Hykin PG, Gregor ZJ. Posterior hyaloid changes following intravitreal triamcinolone and macular laser for diffuse diabetic macular edema. Retina. 2008;28(10): 1435-1442.

6. Cheng CL, Hoh ST, Chuan JC, Wong EY, Koh AH. Acute vitreomacular traction with early spontaneous resolution. Clin Experiment Ophthalmol. 2003;31(2):161-163.

7. Yamada N, Kishi S. Tomographic features and surgical outcomes of vitreomacular traction syndrome. Am J Ophthalmol. 2005;139(1): $112-117$.

8. Yeung CK, Chan KP, Chiang SW, Pang CP, Lam DS. The toxic and stress responses of cultured human retinal pigment epithelium (ARPE19) and human glial cells (SVG) in the presence of triamcinolone. Invest Ophthalmol Vis Sci. 2003;44(12):5293-5300.

9. Narayanan R, Mungcal JK, Kenney MC, Seigel GM, Kuppermann BD. Toxicity of triamcinolone acetonide on retinal neurosensory and pigment epithelial cells. Invest Ophthalmol Vis Sci. 2006;47(2):722-728.

10. Szurman P, Kaczmarek R, Spitzer MS, et al. Differential toxic effect of dissolved triamcinolone and its crystalline deposits on cultured human retinal pigment epithelium (ARPE19) cells. Exp Eye Res. 2006;83(3): 584-592.

11. Kai W, Yanrong J, Xiaoxin L. Vehicle of triamcinolone acetonide is associated with retinal toxicity and transient increase of lens density. Graefes Arch Clin Exp Ophthalmol. 2006;244(9):1152-1159.

12. Valamanesh F, Torriglia A, Savoldelli M, et al. Glucocorticoids induce retinal toxicity through mechanisms mainly associated with paraptosis. Mol Vis. 2007;13:1746-1757.

13. Edelman JL, Lutz D, Castro MR. Corticosteroids inhibit VEGF-induced vascular leakage in a rabbit model of blood-retinal and blood-aqueous barrier breakdown. Exp Eye Res. 2005;80(2):249-258. 
14. Schepens CL, Avila MP, Jalkh AE, Trempe CL. Role of the vitreous in cystoid macular edema. Surv Ophthalmol. 1984;28 Suppl: S499-S504.

15. Sebag J. Age-related changes in human vitreous structure. Graefes Arch Clin Exp Ophthalmol. 1987;225(2):89-93.

16. Udaondo P, Díaz-Llopis M, García-Delpech S, Salom D, Romero FJ. Intravitreal plasmin without vitrectomy for macular edema secondary to branch retinal vein occlusion. Arch Ophthalmol. 2011;129(3): 283-287.

17. Sakuma T, Mizota A, Inoue J, Tanaka M. Intravitreal injection of autologous plasmin enzyme for macular edema associated with branch retinal vein occlusion. Am J Ophthalmol. 2010;150(6):876-882.
18. Haller JA, Qin H, Apte RS, et al; for Diabetic Retinopathy Clinical Research Network Writing Committee. Vitrectomy outcomes in eyes with diabetic macular edema and vitreomacular traction. Ophthalmology. 2010;117(6):1087-1093.

19. Imasawa M, Iijima H. Release of vitreomacular traction following retinal photocoagulation in an eye with branch retinal vein occlusion. Int Ophthalmol. 2009;29(1):63-65.
Clinical Ophthalmology

\section{Publish your work in this journal}

Clinical Ophthalmology is an international, peer-reviewed journal covering all subspecialties within ophthalmology. Key topics include: Optometry; Visual science; Pharmacology and drug therapy in eye diseases; Basic Sciences; Primary and Secondary eye care; Patien Safety and Quality of Care Improvements. This journal is indexed on

Submit your manuscript here: http://www.dovepress.com/clinical-ophthalmology-journal

\section{Dovepress}

PubMed Central and CAS, and is the official journal of The Society of Clinical Ophthalmology (SCO). The manuscript management system is completely online and includes a very quick and fair peer-review system, which is all easy to use. Visit http://www.dovepress.com/ testimonials.php to read real quotes from published authors. 